\title{
The Future of Wood - towards circular bioeconomy
}

\author{
Lauri Hetemäki ${ }^{1,}$ Robert Nasi ${ }^{2}$, Marc Palahí ${ }^{3}$, Paolo Cerutti ${ }^{4}$ and Kai Mausch ${ }^{5}$ \\ December 17, 2021 \\ 1. European Forest Institute (EFI) and University of Helsinki \\ 2. CIFOR-ICRAF \\ 3. European Forest Institute (EFI)
}

This document is part of a series of short papers on "The Future of X", produced as part of foresight-related research supported by the CGIAR Research Program on Policies, Institutions, and Markets, and edited by Keith Wiebe (IFPRI) and Steven Prager (Alliance of Bioversity and CIAT). These short papers are intended to provide a focused, forward-looking perspective on key issues to support discussion on food, land, and water systems transformation. We thank two anonymous reviewers for their comments on an earlier draft.

This is an accepted version presented as a pre-print. It is currently undergoing final revision, editing, and production. A final version will be made available at http://foresight.cgiar.org.

\section{What is the issue?}

The current economic system undermines planetary health, crosses the ecosystem resilience boundaries, and weakens its very functioning. We need to accelerate the transition from the existing global fossil and wasteful economy towards a renewable and resource efficient economy - a circular bioeconomy - that addresses past failures to value natural capital properly. [1]. Increased use of renewable resources and ecological - economic synergies need to form the foundation of a new model. Forests and trees have the potential to be the catalyzer for this transformation. In this transformation, wood as the most versatile renewable material on earth will become increasingly important. Trees will play a key role to mitigate climate change, but we also must recognize their potential to replace fossil-based materials like concrete, steel, plastics or synthetic textiles with renewable materials.

At the same time, natural forests are under pressure from over-exploitation and agricultural expansion. Sustainable, wood-based, solutions are fundamental, but the protection of natural forests is equally important. The key strategy is to maximize synergies and minimize trade-offs between wood use and forest protection. We need to improve our understanding of how the potential can be harnessed in sustainable ways. With $82 \%$ of the wood fuel and $36 \%$ of the industrial roundwood being produced in Africa, Asia and South America, this change needs to involve and consider the needs of the global south [2]. 


\section{What research has been done?}

Foresight and crop models for many agricultural commodities are now relatively well developed and have been applied to many questions. The connection between agricultural production and forests is highlighted by recent findings that $90 \%$ of forest loss is caused by expansion of crop and livestock areas [3]. Industrial use of forest biomass is expected to become increasingly diversified across the world as the global forest industry is undergoing major structural changes. Innovative engineering of wood products for construction, wood used for textiles, chemical industry and many other markets have developed new products and uses for wood, which will change the current demand patterns in multiple ways [4]. This situation makes foresight analysis more difficult and requires the assessment of various scenarios based on expert elicitation, such as Delphi approach [5]. Foresight analysis is often applied to forests, but rarely also on the forest products market outlook. This is especially true in tropical forests, where demography and ongoing intensification of exploitation are taking a growing toll on biodiversity and environmental services [6]. Furthermore, past forest sector foresight research has focused distinctly on European applications and there is a lack of foresight analysis that includes countries of the global South.

\section{What has the research found?}

Foresight analysis has mainly focused on agricultural production directly in efforts to respond to rising food demands and climate change pressures on yields in intensified systems. The implications for trees and forests have mostly been a side note or residual, where the increasing demand for commodity crops results in expansion and therefore deforestation. This is true primarily in low- and middle-income countries [7], where coincidentally also most of the roundwood is produced. Forest sector outlook studies have predicted the need to quadruple [8] wood harvesting while other estimates range from current extraction rates to about a threefold increase [9]. Both studies are based on the simulations of the Global Forest Products Model (GFPM) [10], which is a dynamic economic partial equilibrium model to predict production (supply), consumption (demand), trade, and prices of major forest products in world markets. This would place significant pressure on forest lands, which would be further exacerbated by the entry of new wood-based products on the markets. However, these models do not take into account changing demand structures in current forest products, nor do they consider the new emerging forest products.

A business-as-usual scenario based on simple trends forecasting for future development projects a world roundwood production increase by $16 \%$. However, various demand-curbing projections based on 'what-if' scenarios and taking into account structural changes imply possibility for significant decline for some traditional forest products. Declining trends in demand for traditional communication papers (e.g. newsprint, magazine paper) could lower wood demand from $544 \mathrm{Mm}^{3}$ in 2018 to $84 \mathrm{Mm}^{3}$ by 2050 . Another reduction could come from 
changing energy consumption, and by that, reduce the demand e.g. for wood charcoal. This would also have significant co-benefits, such as, climate mitigation benefits, health benefits and freeing time for other activities, especially for women and children, who often collect the wood [11-14]. Finally, many of the new forest bioproducts (e.g. biochemicals, biofuels, bioplastics) will be based on the raw material side-streams of current products, and will use the current raw materials more efficiently, such as black liquor, lignin, bark, forest residues, etc. [4]. Therefore, the need to increase wood production for these new products could be moderate.

Based on these scenarios, there is significant scope to use wood resources more efficiently. A significant amount of current production could be better used in new products that replace non-renewable resources and products. However, there is a general lack of systematic and detailed up-to-date studies of the future global wood demand taking into account the structural changes in the world forest products markets. Given these gaps, we do not have a good picture of what will be the future demand for forest products and forest resources, and therefore, the resulting impacts e.g. on investments, climate mitigation and biodiversity. New research on these impacts is urgently needed to detangle these structural changes and develop solutions that both enhance environmental benefits from forests and make better use of forest products replacing fossil-based materials.

Significant climate mitigation and sustainability impacts can be achieved by substituting fossilbased, and other problematic products (e.g., cotton) with wood-based products, which has been demonstrated in detail for some countries $[15,16]$. The interest in the opportunities that wood-based products may provide by replacing fossil raw materials and products is still a fairly recent phenomenon at the global scale. Although the circular bioeconomy landscape is promising, it is also broad, complex, and even confusing - not short of wicked problems. Against the background of these significant shifts in the world forest products market structures, it is critically important to ensure these new structures are also based on environmentally sustainable options (e.g., not compromising biodiversity). Moreover, it is important to take care of the social sustainability. For example, when moving to reduce wood fuel consumption in Africa, it would be essential to ensure that the current users of wood energy have an opportunity to transform to the new situation, and those earning income from the wood fuel selling/collection will have other income sources. For this, it would be important to design policies, investment subsidies, technology transfer help, new income opportunities, etc. to support the transition to more efficient wood fuel use or away from it.

\section{What gaps deserve further work?}

Foresight analysis for wood demand and supply has not received the same attention as other commodities and products. Agricultural expansion and increasing demands for roundwood pose dual threats to forests already. Thus, new wood-based products to replace fossil-based 
materials need to be implemented in a way that reduces these pressures, rather than increases them. The historically large structural changes ongoing in the forest products markets will require non-traditional approaches also to wood demand and supply analysis that combine qualitative scenario building and quantitative modeling. This would also allow better understanding of the implications of the recent and future changes of wood demand for forests, climate mitigation and biodiversity and the full range of services forests provide. In addition, there are significant parts of the wood sector for which data is lacking, e.g., domestic demand and consumption in many tropical countries, and illegal harvesting and trading in both temperate and tropical ones, which further complicates modeling of future trends. Investing in improved understanding of the possible future changes and their implications on livelihoods and the environment is essential. This could lead to better-informed policies and monitoring systems, and ultimately a more sustainable sector. Better polices would help reduce the current unsustainable forest extraction, and enhance the positive synergies and minimize trade-offs between wood production, climate mitigation and biodiversity and the other ecosystem services that global forests provide [1].

In summary, there are great opportunities to better use wood as a non-fossil fuel-based raw materials and tackle climate change, as well as to achieve Sustainable Development Goals. However, there is an urgent need to invest in more research on how this could be best implemented in a sustainable way and in different regions, especially in the global South.

\section{References}

1. Palahí, M., Pantsar, M., Costanza, R., Kubiszewski, I., Potočnik, J., Stuchtey, M., Nasi, R., Lovins, H., Giovannini, E., Fioramonti, L., Dixson-Declève, S., McGlade, J., Pickett, K., Wilkinson, R., Holmgren, J., Trebeck, K., Wallis, S., Ramage, M., Berndes, G., Akinnifesi, F.K., Ragnarsdóttir, K.V., Muys, B., Safonov, G., Nobre, A.D., Nobre, C., Ibañez, D., Wijkman, A., Snape, J., Bas, L. 2020. Investing in Nature as the true engine of our economy: A 10-point Action Plan for a Circular Bioeconomy of Wellbeing. Knowledge to Action 02, European Forest Institute. https://doi.org/10.36333/k2a02

2. Hetemäki, L., Palahí, M. and Nasi, R. 2020. Seeing the wood in the forests. Knowledge to Action 01, European Forest Institute. https://doi.org/10.36333/k2a01)

3. FAO 2021. FAO Remote Sensing Survey reveals Tropical rainforests under pressure as agricultural expansion drives global deforestation. https://www.fao.org/3/cb7449en/cb7449en.pdf

4. Hetemäki, L. \& Hurmekoski, E. 2020. Forest bioeconomy development: markets and industry structures. In The Wicked Problem of Forest Policy (edited by William Nikolakis and John Innes). Cambridge University Press. doi.org/10.1017/9781108684439

5. Hurmekoski, E., Jonsson,R., Korhonen, J., Jänis, J., Mäkinen, M., Leskinen, P. \& Hetemäki, L. 2018. Diversification of the forest industries: Role of new wood-based products. Canadian Journal of Forest Research. 2018, 48(12): 1417-1432, https://doi.org/10.1139/cjfr-2018-0116

6. Francis E. Putz and Claudia Romero, 2014. Futures of Tropical Forests (sensu lato). BIOTROPICA 46(4): 495-505 2014. 
7. Winkler, K., Fuchs, R., Rounsevell, M. et al. Global land use changes are four times greater than previously estimated. Nat Commun 12, 2501 (2021). https://doi.org/10.1038/s41467-021-22702-2

8. WWF (2011) Living Forest Report. WWF Int.

https://awsassets.panda.org/downloads/living_forests_chapter_1_26_4_11.pdf

9. Buongiorno, J., Zhu, S., Raunikar, R. \& Prestemon, J.P. 2012. Outlook to 2060 for world forests and forest industries: a technical document supporting the Forest Service 2010 RPA assessment, U.S. Department of Agriculture Forest Service, Southern Research. https://www.srs.fs.usda.gov/pubs/gtr/gtr_srs151.pdf

10. Joseph Buongiorno, Shushuai Zhu, Dali Zhang, James Turner, and David Tomberlin 2003. The Global Forest Products Model (GFPM): Structure, Estimation, Applications. Academic Press.

11. Alexandra Tyukavina, Matthew C. Hansen, Peter Potapov, Diana Parker, Chima Okpa, Stephen V. Stehman, Indrani Kommareddy, Svetlana Turubanova, 2018. Sci. Adv. 2018;4: eaat2993.

12. Copenhagen Centre on Energy Efficiency 2015. Accelerating Energy Efficiency: Initiatives and Opportunities, Africa. Copenhagen Denmark. https://unepdtu.org/wp-content/uploads/2015/08/africanregional-report.pdf

13. Ouedraogo, N. 2017. Africa energy future: Alternative scenarios and their implications for sustainable development strategies. Energy Policy; 457-471. https://doi.org/10.1016/j.enpol.2017.03.021

14. World Bank 2011. Wood-Based Biomass Energy Development for Sub-Saharan Africa. https://siteresources.worldbank.org/EXTAFRREGTOPENERGY/Resources/7173051266613906108/BiomassEnergyPaper WEB Zoomed75.pdf

15. Hurmekoski, E., Myllyviita, T., Seppälä, J., Heinonen, T., Kilpeläinen, A., Pukkala, T., Mattila, T., Hetemäki, L., Asikainen, A., Peltola, H. 2020. Impact of structural changes in wood-using industries on net carbon emissions in Finland. Journal of Industrial Ecology. January 2020, https://doi.org/10.1111/jiec.12981. 